\title{
Configurações
}

Revista de sociologia

\section{O contacto no acolhimento familiar. Discursos, representações e desafios para o desenvolvimento da relação entre famílias e profissionais}

Contact in foster care. Discourses, representations and challenges for the development of the relationship between families and professionals Contact dans le placement familial. Ce que pensent les enfants, les familles et les professionnels

João M. S. Carvalho, Paulo Delgado and Vânia S. Pinto

\section{OpenEdition}

\section{Journals}

Electronic version

URL: http://journals.openedition.org/configuracoes/7317

DOI: $10.4000 /$ configuracoes. 7317

ISSN: 2182-7419

Publisher

Centro de Investigação em Ciências Sociais

Printed version

Number of pages: 31-52

ISSN: 1646-5075

\section{Electronic reference}

João M. S. Carvalho, Paulo Delgado and Vânia S. Pinto, "O contacto no acolhimento familiar.

Discursos, representações e desafios para o desenvolvimento da relação entre famílias e

profissionais », Configurações [Online], 23 | 2019, Online since 28 June 2019, connection on 30 June

2019. URL : http://journals.openedition.org/configuracoes/7317 ; DOI : 10.4000/configuracoes.7317 
Carvalho, João M.S.; Delgado, Paulo; Pinto, Vânia S. - 0 contacto no acolhimento familiar. Discursos, representações e desafios para o desenvolvimento da relação entre famílias e profissionais. Configurações, vol. 23, 2019, pp. 31-52.

\section{0 contacto no acolhimento familiar. Discursos, representações e desafios para o desenvolvimento da relação entre famílias e profissionais}

JOÃO M. S. CARVALHO*

CICS.NOVA.UMinho, InED-ESE-IPP, UNICES-Instituto Universitário da Maia, Portugal

PAULO DELGADO**

InED, Escola Superior de Educação do Porto / CIEC, Universidade do Minho, Portugal

VÂNIA S. PINTO***

InED, REES Centre, Department of Education, University of Oxford, UK

\section{Resumo}

Este estudo pretende refletir sobre os resultados do contacto no acolhimento familiar, identificar os obstáculos para a sua realização e analisar o modo como as famílias de origem, as famílias de acolhimento e os profissionais percecionam esta realidade. É usada uma triangulação metodológica, com base na análise de inquéritos e entrevistas realizadas com aqueles atores numa amostra de 10 acolhimentos no distrito do Porto. Os resultados permitem concluir que é importante: desenvolver processos de cooperação regulada entre os atores; desenvolver um trabalho mais atento e disponível com os pais biológicos; disponibilizar recursos que facilitem as visitas; e promover processos de formação e de apoio aos atores que abordem as questões da diversidade cultural.

Palavras-chave: Acolhimento familiar, contacto, famílias de acolhimento, famílias de origem, profissionais.

\footnotetext{
*E-mail: jcarvalho@ismai.pt

** E-mail: pdelgado@ese.ipp.pt

***E-mail: vania.pinto@lmh.ox.ac.uk
} 


\begin{abstract}
Contact in foster care. Discourses, representations and challenges for the development of the relationship between families and professionals

This study intends to reflect on the results of contact, to identify the obstacles to its accomplishment and to analyse how the families of origin, the foster families and the professionals of the technical teams are related, as well as how they perceive and evaluate the reality.

A methodological triangulation has been used, based on the analysis of the interviews with the families of origin, the foster families and the professionals of the technical teams, carried out in a sample of 10 hosts of the Porto district.

The results show that it is important: (1) to develop processes of regulated cooperation, which improve communication and the relationship between the professionals and the carers, and essentially between these actors and the families of origin; (2) to develop a more attentive and available work with the parents, to support the separation, monitoring and recovery of parental competences; (3) to provide resources to facilitate travel and support the expenses of the visits; and (4) to promote training and educational support procedures that clarify the processes, roles, purposes and potential outcomes of decisions, addressing specifically issues of cultural diversity.
\end{abstract}

Keywords: Foster care, contact, foster families, birth families, professionals.

\title{
Résumé
}

Contact dans le placement familial. Ce que pensent les enfants, les familles et les professionnels

Cette étude a pour but de réfléchir sur les résultats du contact dans le placement familial, d'identifier les obstacles à son accomplissement et d'analyser comment sont liées les familles d'origine, les familles d'accueil et les professionnels perçoivent cette réalité. Une triangulation méthodologique est utilisée, basée sur l'analyse d'enquêtes et d'entretiens avec ces acteurs dans un échantillon de 10 hôtes du district de Porto.

Les résultats montrent qu'il est important de: développer des processus de coopération réglementés entre les acteurs; développer un travail plus attentif et disponible avec les parents; fournir des ressources qui facilitent les visites; et promouvoir des processus de formation et de soutien pour les acteurs que traitent des questions de diversité culturelle.

Mots-clés: Placement familial, contact, familles d'accueil, familles d'origine, professionnels.

\section{A importância e os desafios do contacto}

As crianças e os jovens são afetados pela violência doméstica de múltiplas formas, com consequências imediatas a médio e longo prazo. $\mathrm{O}$ impacto dos maus tratos, seja qual for o seu tipo, reflete-se ao nível emocional, cognitivo, moral, biológico e social (Cairns, 2002; Foxon e Fuller, 2007). O conceito de maus tratos é polissémico e varia de acordo com a época histórica e com o contexto social. Na perspetiva de Garbarino e Eckenrode, define-se como "qualquer ato de omissão ou ação por um pai ou tutor que, por uma combinação 
de valores e avaliações de peritos profissionais da comunidade, se considera inadequado e prejudicial" (1999: 22).

Paradoxalmente, é no seio da própria família que a criança corre mais riscos de ser maltratada (Comissão Nacional de Promoção dos Direitos e Proteção das Crianças e Jovens, 2016). Nestas circunstancias, a sociedade tem o dever de atuar para garantir a proteção das crianças, através da intervenção dos serviços sociais locais, e/ou das entidades com poder judicial. A intervenção tem por finalidade assegurar as necessidades individuais da criança no presente $\mathrm{e}$ para o futuro, uma vez que as sociedades necessitam de contar com cidadãos saudáveis e participativos (Gilbert, Parton, e Skivenes, 2011).

Nos casos mais graves, em que se gera um maior perigo para a segurança, e a integridade física e emocional, pode ser necessário retirá-la da sua família, passando a criança a viver num novo contexto, com uma família adotiva ou de acolhimento. Na maioria dos países com uma economia industrial ou pós-industrial, a colocação em residências é considerada como o último recurso, para fazer face a situações excecionais, sobretudo para crianças mais velhas ou jovens, com problemas de saúde mental ou outras necessidades especiais (Courtney e Iwaniec, 2009; Del Valle e Bravo, 2013).

Nas situações em que a criança é retirada do seu contexto de vida, o impacto da intervenção é substancial, uma vez que temos de associar às possíveis consequências dos maus tratos, a rutura das relações e hábitos de vida no seu quotidiano familiar, social e educativo, obrigando a uma integração num meio diferente, parcial ou totalmente desconhecido, que suscita uma adaptação súbita e radical (Delgado, 2011). E é neste contexto que o contacto com a família de origem pode desempenhar um papel fundamental, nomeadamente pela manutenção da ligação da criança ao seu passado identitário, evitando a rutura das relações e do capital emocional que são parte de si (McWey, Acock, e Porter, 2010; Coakley, 2013). Para além disso, como o projeto de vida da criança é, em princípio, a reunificação, então a manutenção do contacto é crucial para que não se rompam os laços familiares (McWey, 2000; McWey e Mullis, 2004).

O contacto não é um processo fácil, sublinhe-se. As dificuldades associadas ao contacto entre a criança acolhida, em família de acolhimento ou instituição, e a sua família de origem, devem-se ao facto de relacionarem diversos protagonistas, assim como sentimentos muito variados, como a hostilidade, a ambivalência, o conflito, a desqualificação ou a saudade, com avanços e recuos que podem levar a comportamentos cooperativos ou a rivalidades e mal-entendidos (Carvalho e Delgado, 2014; Delgado et al., 2016). Os resultados obtidos dependem de um vasto e complexo grupo de fatores interdependentes, como a disponibilidade da família de origem, o tempo de permanência no acolhimento, os tipos de maus tratos sofridos, o percurso no sistema de proteção, a postura dos acolhedores, o acompanhamento prestado pela equipa de acolhimento, 
etc. (Moyers, Farmer, e Lipscombe, 2006; Osborn e Delfabbro, 2009; Sen e Broadhurst, 2011).

O contacto constitui um campo por excelência de diversidade e de relação intercultural. Delgado, Pinto e Carvalho (2014) refletem sobre os desafios que o contacto apresenta às famílias de acolhimento, porque as coloca face a comportamentos e valores da família de origem, os quais se encontram, com frequência, distantes dos que são socialmente aceitáveis. Esta é uma questão central no processo de acolhimento: como lidar com a diferença de padrões e de comportamentos, como a gerir e até que ponto a aceitar. Estes autores concluem que a tolerância é fundamental, devendo a relação com a família de origem pautar-se pelo respeito, pela escuta e pelo debate, de modo a viabilizar um compromisso de encontro que põe de lado a indiferença e que se rege por princípios, regras e limites. Acresce que a existência de problemas no contacto é uma das principais razões para a rutura do acolhimento, a par com os problemas comportamentais da criança (Vanderfaeillie, Van Holen, e Coussens, 2008).

Quando o contacto é positivo, produz efeitos benéficos na criança, como o fortalecimento da sua identidade física e genealógica; tranquilizando a criança sobre a situação dos pais biológicos, permitindo que sinta que eles se importam com ela, demonstrando amor e afeto; ajudando a acalmar a ansiedade e um possível sentimento de culpa; reduzindo os sentimentos de perda e de rejeição; e promovendo a sua autoestima (Triseliotis, 2010).

Assim, pretende-se conhecer em que medida os atores num processo de acolhimento familiar partilham das mesmas perspetivas sobre cada caso, procurando detetar inconformidades e oportunidades de melhoria do próprio processo.

\section{Metodologia}

\subsection{Método}

Este estudo resulta de um projeto em curso integrado no InED, o Centro de Investigação em Inovação e Educação da Escola Superior de Educação do Porto (ESEP), intitulado "Contacto no acolhimento familiar: padrões, resultados e modelos de gestão", que tem como objetivo geral analisar os resultados do contacto entre a criança ou jovem em acolhimento familiar e a sua família de origem, bem como as causas da sua inexistência ou cessação.

Foram aplicados inquéritos semelhantes aos profissionais das equipas técnicas de acolhimento e às famílias de acolhimento, tendo os dados sido tratados estatisticamente com recurso ao software SPSS. Posteriormente, foram realizadas entrevistas com um grupo de famílias de origem, famílias de acolhimento e profissionais. Recorreu-se à análise de conteúdo dos textos das entrevistas utilizando o software MAXQDA 10.0, tendo-se agrupado a informação em dimensões temáticas (categorias), mutuamente exclusivas. 


\subsection{População e amostra}

Em Portugal, encontravam-se, em 2016, acolhidas 261 crianças em acolhimento familiar (Instituto da Segurança Social, 2017), das quais apenas 18 tinham até 5 anos de idade. A Lei de Proteção de Criança e Jovens em Perigo em vigor (Lei $n^{\circ} 142 / 2015$, de 8 de setembro) considera o acolhimento familiar como o contexto preferencial de acolhimento para crianças até aos 6 anos, o que não tem sido concretizado na prática. Urge disseminar a medida de acolhimento familiar, uma vez que, atualmente, só no Norte do país e na Madeira têm tido colocadas crianças em famílias de acolhimento.

Em maio de 2014, os questionários respondidos pelos profissionais das equipas de acolhimento e pelas famílias de acolhimento permitiram recolher dados sobre 221 crianças e jovens em acolhimento familiar no distrito do Porto, as quais correspondiam a 59,1\% do total de crianças acolhidas em Portugal (Instituto da Segurança Social, 2017), sendo que 200 estavam acolhidas em famílias recrutadas pelo Instituto da Segurança Social, I.P., e 21 em famílias recrutadas pela Instituição Particular de Solidariedade Social "Mundos de Vida».

A partir desta amostra de 221 crianças e jovens escolheu-se, aleatoriamente, 17 crianças e jovens que tinham contacto com a família de origem, com base em três critérios: sexo, escalão etário e tempo de acolhimento. Em 13 casos foi possível agendar entrevistas com os profissionais que acompanhavam o seu acolhimento, as suas famílias de origem e respetivas famílias de acolhimento. No decorrer das entrevistas, três famílias de origem desistiram do estudo, ficando a amostra final num total de 10 casos. Estes participantes descreveram o contexto de acolhimento das crianças e jovens, os quais tinham entre os sete e os vinte e dois anos de idade, com uma média de 11,6 anos ( $\mathrm{DP}=4,84$ ), e sendo cinco do sexo feminino e cinco do sexo masculino. Estas crianças e jovens encontravam-se em acolhimento familiar em média há 3,5 anos, mais especificamente entre dois meses e 15 anos. Foi assegurado o anonimato, sendo os nomes das crianças fictícios.

\subsection{Instrumentos de recolha de dados}

O guião das entrevistas realizadas com as famílias de origem (FO), as famílias de acolhimento (FA), e os profissionais da equipa de acolhimento $(\mathrm{P})$, recolhem a mesma informação, uma vez que se pretende compreender como os diferentes intervenientes percecionam a mesma realidade.

Para efeitos deste trabalho, analisaram-se apenas os dados referentes à informação sociodemográfica da criança ou jovem; às perspetivas dos profissionais, famílias de origem e de acolhimento relativamente às reações que as visitas produzem na criança, ao grau e tipo de dificuldades na realização das visitas; à qualidade das relações entre os 
diferentes atores (FO, FA e P); sobre o desempenho dos profissionais; e sobre a atitude da criança ou jovem e dos outros atores relativamente ao acolhimento.

\section{Análise de dados}

No que refere ao contacto e mais especificamente à visita, um dos indicadores a ter em consideração é a forma como a criança ou o jovem se sente e quais as reações que manifesta, segundo a perspetiva dos profissionais, das famílias de origem e de acolhimento. Ao se avaliar o momento anterior ao contacto, destaca-se que, perante os 10 casos em análise, as reações manifestadas por cada criança ou jovem são percecionadas de forma diferente pelos intervenientes. Nomeadamente as famílias de acolhimento dividem-se entre as reações de alegria, indiferença ou ansiedade; os profissionais, na sua maioria, evidenciam a ansiedade como reação dominante; e, por sua vez, as famílias de origem apenas evidenciam reações de alegria. Depreende-se que as famílias de origem têm uma perspetiva mais positiva que os profissionais e os acolhedores. Em nenhum dos casos os três intervenientes estão em concordância, e apenas em 2 casos existe concordância entre família de acolhimento e o profissional.

Esta discordância entre perspetivas transforma-se numa concordância plena entre todos os intervenientes em 6 dos 10 casos quando se avalia as reações das crianças ou jovens durante a visita, evidenciando as reações de alegria. Nos outros quatro casos existe concordância entre, pelo menos, o acolhedor e o profissional ou o acolhedor e a família de origem (Figura 1).

Figura 1. Perceção dos autores sobre a reação da criança ou do jovem durante as visitas

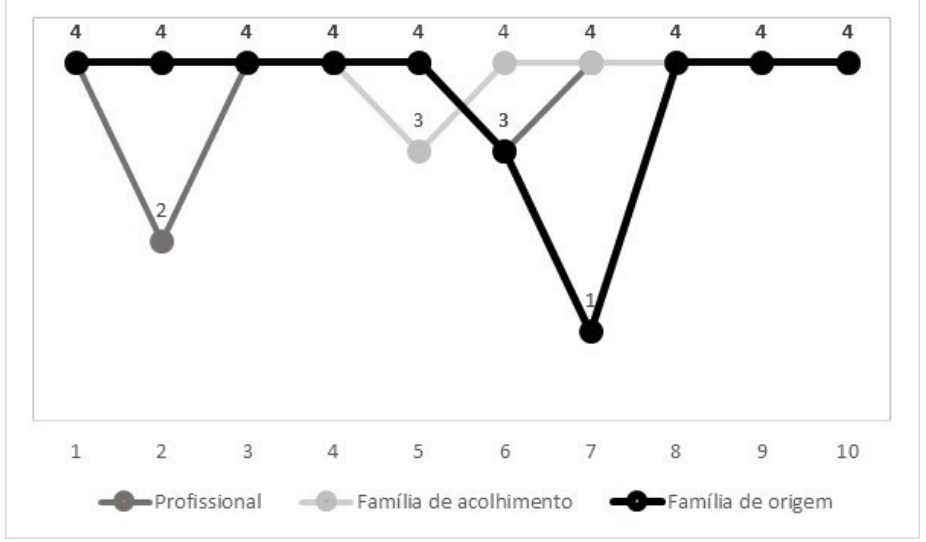

A acolhedora do Renato (7 anos) identifica as reações da criança como de alegria e complementa com o facto de que "ela gosta muito do pai". 
Por sua vez, a acolhedora da Amélia (8 anos), ao expressar a sua opinião sobre as visitas refere que "sim, sim, sim. ... o objetivo será sempre o regresso à família, eu acho que tem mesmo que continuar a haver...”. Apesar das perspetivas maioritariamente positivas e concordantes entre os diferentes intervenientes, é possível assinalar algumas preocupações nestes contactos. A profissional que acompanha a Joana (16 anos) considera que "é um momento muito benéfico para ela, só que lá está, depois chegamos todos à conclusão que a menor não consegue muito bem gerir essa euforia e essa felicidade, porque depois acaba por confundir um bocadinho se é positivo o meio ou não, ou seja ela depois... ela tem muita expectativa no regresso, e nós temos trabalhado com ela". A situação da Anabela (12 anos) é semelhante. As perspetivas dos intervenientes face às reações das crianças ou jovens após a visita revelam uma vez mais um elevado grau de discordância. Os acolhedores identificam diferentes reações, as quais variam entre agitação, alegria, indiferença e tristeza; os profissionais, por sua vez, identificam reações entre a alegria e a angústia; enquanto as famílias de origem apenas mencionam tristeza. Tal como face às reações antes da visita, as famílias de origem têm uma perspetiva mais favorável em relação ao seu papel na vida das crianças. É de notar que em nenhum dos casos os três intervenientes estão em concordância, existindo apenas 2 casos de concordância entre família de acolhimento e o profissional.

As dificuldades sentidas ao nível do contacto entre a criança ou jovem e a família de origem são percecionadas com diferentes intensidades pelos intervenientes. Como se pode verificar na figura 2, os acolhedores consideram existir dificuldades significativas em dois casos, e muito significativas em quatro situações. Por sua vez, as famílias de origem consideram que apenas em um caso as dificuldades são muito significativas, face a quatro casos em que as dificuldades existentes são consideradas significativas. Os profissionais consideram que as dificuldades não estão tão presentes, uma vez que verbalizam dificuldades que podem ser classificadas como muito significativas apenas em um caso, significativas em três casos, e reduzidas ou inexistentes em seis casos. Apenas existe concordância entre os três intervenientes, face ao grau de dificuldade, em um caso, sendo as famílias de origem e os acolhedores o par com maior concordância, em 50\% dos casos. 
Figura 2. Grau de dificuldade percecionado pelos atores ao nível do contacto

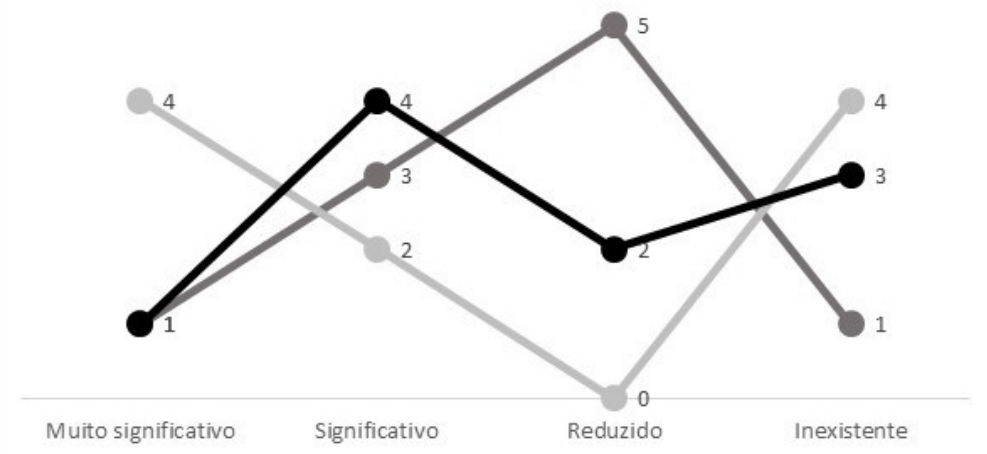

O tipo de dificuldades enunciadas varia substancialmente de acordo com o interveniente em questão. A família de origem considera como principal dificuldade a falta de dinheiro, afetando a frequência das deslocações (Figura 3). É o caso de uma mãe que reconhece a dificuldade em suportar os custos associados às deslocações: "Estou desempregada, a fazer formação (...) É difícil pagar os transportes. Mas nunca faltei; desde fevereiro até agora, venho sempre" (FO2). Esta dificuldade é evidente noutra entrevista, quando se afirma "dificuldades só mesmo económicas, por causa dos transportes" (FO7). Outro testemunho declara simplesmente: "É longe, demoro 45 minutos a pé (fala das suas dificuldades para caminhar) (FO3).

Figura 3. Principais dificuldades ao nível do contacto

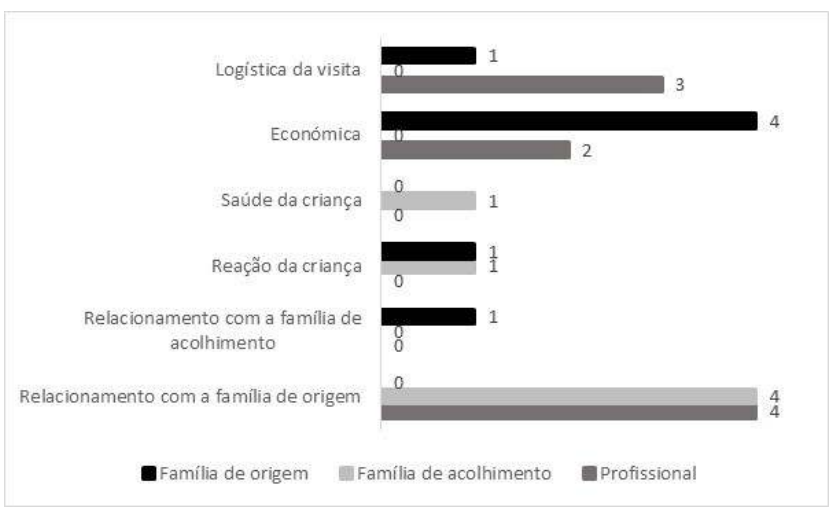


Os profissionais enunciam, maioritariamente, as dificuldades relacionais com a família de origem e as questões logísticas da visita. É o caso do P10, quando declara "não há dificuldades, é muito pacífico, tomara nós que houvesse, às vezes apetecia que houvesse algumas dificuldades porque era motivo ou sinal de que esta mãe (...) pretendia alguma coisa, mas não, infelizmente não. Talvez a maior dificuldade seja a passividade envolvida”. Noutro caso, o profissional entrevistado destaca a agressividade em termos do discurso na relação mãe-filho (P8).

Os relatos dos acolhedores incidem, por sua vez, nas questões relacionais com a família de origem. É o caso de uma acolhedora que declara que o maior problema é o incumprimento das visitas, com um impacto negativo na criança acolhida, pois segundo a mesma acolhedora, "se vocês tivessem um filho também não iam gostar de ver que ele estava ali à espera de uma coisa que ele acha que é tão querida, porque ele adora a mãe, e depois aquela pessoa vai-lhe falhar. Isso é complicado" (FA1).

O distanciamento é referido noutro caso (FA7): “a mãe devia fazer mais perguntas aos filhos, mostrar-se mais interessada por aquilo que se passa na vida dele. Não é só aquilo que se vê aparente, ela às vezes podia aprofundar mais um bocadinho..." E a acolhedora reforça esta ideia: “ele também gostava que a mãe fosse diferente às vezes. Eu acho que ele gostava de me transportar a mim para a mãe, porque ele adorava viver com a mãe, mas ele imagina uma mãe que na realidade não é a mãe dele, certo. E eu noto isso no menino, tem uma adoração pela mãe. Quando a mãe vai embora, já só vê um braço e ele continua a dizer adeus. E, portanto, isso é uma coisa... a minha mãe veio-me ver... eu sei lá, não sei” (FA7).

Sublinhe-se que não existe concordância entre os trêsintervenientes, porém os profissionais e os acolhedores enunciam as mesmas dificuldades face a dois casos.

Perante estes discursos, emerge a necessidade de se investir na formação das famílias de acolhimento e das famílias de origem com vista a melhor prepará-los para este contexto e para as dificuldades associadas. A maioria dos intervenientes considera que a formação é essencial. Destaca-se que, enquanto os acolhedores consideram que a sua formação é importante, tal como as famílias de origem, os profissionais na sua maioria consideram que a formação deveria ser preferencialmente direcionada para as famílias de acolhimento. Por exemplo, uma profissional que acompanha o Renato, declara defender "muito a formação nas famílias de acolhimento, por várias razões, elas dizem sempre: ah, eu cuido dele como se fosse um filho, mas não é bem assim, não é? Eles têm outro tipo de obrigações, aliás (...) e outro tipo de competências também”.

Apenas um profissional das equipas de acolhimento menciona que a formação deveria abranger todos os intervenientes, o que se justifica pela "motivação de parte a parte, preparação de parte a parte, da família de acolhimento, da criança e da família de origem. Ter o conhecimento de como funciona o processo todo para estarem preparados, mesmo antes da visita".

Deque modo os profissionais das equipas de acolhimento, as famílias de origem e as famílias de acolhimento, se percecionam, relacionam e avaliam a colocação? 
$\mathrm{Na}$ figura 4 evidencia-se que, nestes dez casos, as relações entre os acolhedores e os profissionais são vistas como de melhor qualidade do que as relações entre as famílias de origem e os profissionais, na perspetiva de todos os atores. O seguinte excerto descreve as dificuldades sentidas pelo P9 na comunicação com a família de origem: "Não é muito fácil porque a Dona P. nunca tem poiso certo e para além disso muda constantemente de telemóvel, portanto, nunca sei muito bem (...) desde janeiro que ando a marcar entrevistas, em contexto de atendimento, não aparece, portanto, desmarca constantemente. A próxima estava agendada para a semana passada e não apareceu, telefonou ontem a marcar nova entrevista, já lhe agendei nova entrevista, mas não sei se irá aparecer”.

Ao nível da concordância entre estes dois conjuntos grupais destaca-se que é a mesma, ou seja 50\% dos acolhedores e profissionais, e $50 \%$ das famílias de origem e profissionais estão em concordância face à forma como avaliam a qualidade da relação que têm.

Figura 4. Comparação da avaliação da relação entre atores, em termos de qualidade

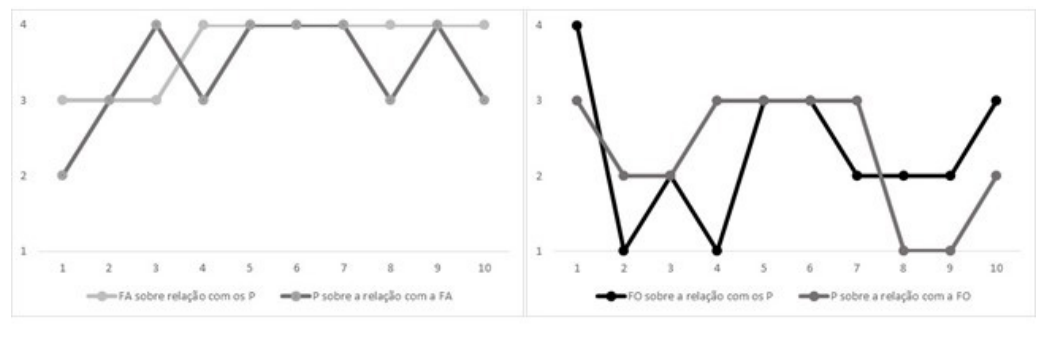

4 - Muito bom ; 3 - Bom ; 2 - Razoável ; 1 - Medíocre

Importa igualmente analisar como as duas famílias se relacionam, uma vez que perante a existência de contactos certamente serão estes os dois intervenientes com maior interação, por se encontrarem frequentemente no início e término das visitas e porque, na maioria dos casos, as visitas decorrem na casa das famílias de acolhimento (Delgado et al., 2016).

É notório que, face aos dez casos, as famílias de origem percecionam a relação com os acolhedores como de maior qualidade (com a exceção de dois casos), sendo possível extrair através do seu discurso que a classificam, maioritariamente, como razoável ou boa, comparativamente aos acolhedores que consideram a qualidade da relação com as famílias de origem como razoável (Figura 5). Existe concordância em apenas 4 casos. 
A dificuldade de comunicação é ilustrada no seguinte testemunho da FA4: "foi sempre difícil, com esta família (...) Com o senhor J. e a senhora $\mathrm{N}$. não, ele só sabe berrar. $\mathrm{Na}$ ideia deles, se não existissem famílias de acolhimento não lhes tiravam os filhos. E na ideia dele se os filhos tivessem que sair de casa, mais vale irem para um colégio interno. Ele disse isso ao juiz, que preferia que fossem para um colégio. Não aceitam famílias de acolhimento".

Figura 5. Comparação da avaliação da relação entre as FA e as FO, em termos de qualidade

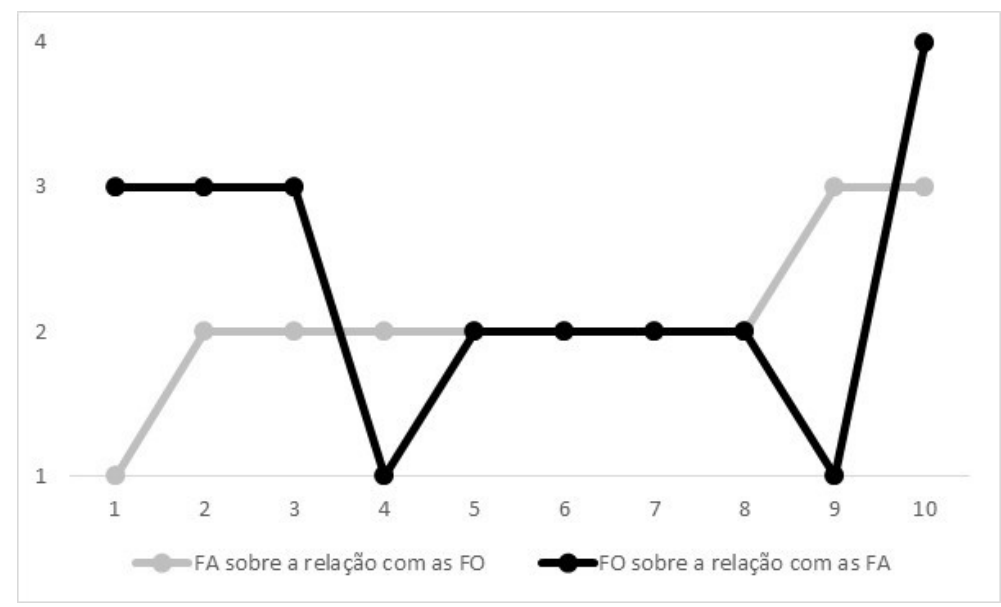

4 - Muito bom ; 3 - Bom ; 2 - Razoável ; 1 - Medíocre

Surgem outras circunstâncias em que a comunicação até é fácil, mas nem sempre produz os efeitos esperados. De acordo com a FA7, "Eu consigo comunicar facilmente com ela ou com a tia até se for preciso. Só que depois, aquilo que eu digo, ela diz-me tudo que sim, que sim, que sim, mas não vai cumprir nem metade do que disse, ou do que eu tento explicar-lhe, ou mostrar-lhe... Ela não é uma pessoa assim muito, não dá muito feedback a nível de conversação".

Face ao desempenho da equipa de acolhimento, que engloba a perceção face ao trabalho que os profissionais desenvolvem, os apoios que prestam e as solicitações do próprio, os acolhedores mostram-se muito mais satisfeitos que as famílias de origem (Figura 6). Os acolhedores avaliam o desempenho dos profissionais como bom ou muito bom, face às famílias de origem que classificam maioritariamente como insuficiente. 
Figura 6. Avaliação do desempenho da equipa de acompanhamento por parte das FA e das FO.

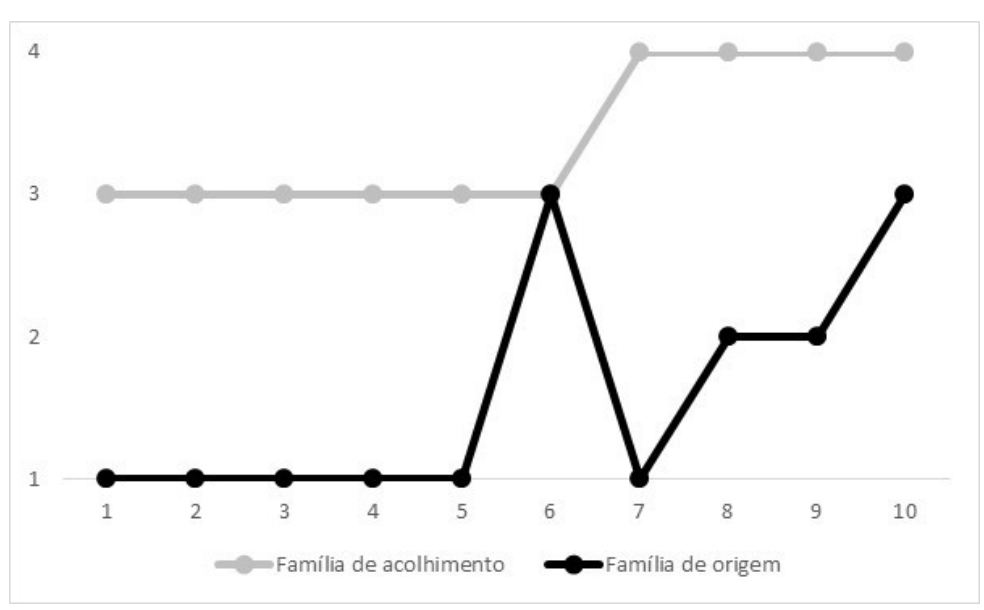

4 - Muito bom ; 3 - Bom ; 2 - Suficiente ; 1 - Insuficiente

Relativamente à frequência e ao tipo de comunicação, a FA3 declara que "contactamos as vezes que quisermos, para mostramos as nossas preocupações, pedir conselhos, o que quer que seja, enfim, eles estão sempre... se não estiverem disponíveis, passado um bocadinho estão-nos a ligar, ao fim de semana, a qualquer hora. Isso aí não há nada a apontar. Excecional". Esta família avalia o trabalho desenvolvido pela equipa técnica como muito bom e acrescenta: "aliás, se não fosse com o apoio da equipa e assim, trabalhar nos moldes em que eles trabalham, não conseguíamos”.

Uma das famílias de origem, pelo contrário, considera que a frequência dos contactos com a equipa técnica é insuficiente: "O juiz disse para ela vir uma vez por mês para ver a casa como estava, se a gente tinha condições... os meus filhos estão lá há 4 anos e se ela veio a minha casa 7 ou 8 vezes foi o máximo". Esta opinião é reforçada com um protesto: “é difícil, nós queremos falar com o juiz, é quando ela quer e não quando a gente quer!” (FO3). Noutro caso, a família de origem classifica como insuficiente o contacto com o profissional da equipa de acolhimento, da qual não tem o número telefónico: “A comunicação com a equipa de acolhimento é difícil porque a Dona R. (a acolhedora) tem mais contactos com a equipa de acolhimento que com nós” (FO4).

Apenas num caso existe concordância entre ambos os intervenientes e em $70 \%$ dos casos a distância entre estas avaliações é equitativa, correspondendo a uma distância de dois graus da escala (Figura 6).

Os profissionais da equipa de acolhimento avaliaram o desempenho das famílias de acolhimento dentro dos mesmos parâmetros e consideraram que 
$70 \%$ dos acolhedores apresentam um desempenho muito bom e 30\% bom. O testemunho do P5 ilustra a relação positiva que os profissionais mantêm com as famílias de acolhimento: "sempre nos procurou para pedir ajuda para o que quer que fosse, para as dúvidas que tivesse, para orientar a jovem, mesmo quando ela ainda frequentava a escola, e foi complicado porque a escola tende a empurrar estes meninos (crianças com deficiência) para estruturas especializadas, tentamos manter esta jovem o máximo de tempo possível, integrada, com suporte da escola, atendimento, isso tudo, portanto é uma pessoa que revelou sempre qualidades excelentes para o desempenho da atividade".

Por seu turno, o P10 avalia de modo semelhante o desempenho de uma família de acolhimento, quando afirma: “É muito bom, é uma família que tem um perfil bastante bom, com muita sensibilidade para a questão, muito preocupada em evoluir e melhorar, muito envolvida nos projetos de vida dos meninos, com uma grande capacidade de relação com as famílias de origem”. Esta família já teve vários processos, o primeiro dos quais uma criança que foi para adoção, uma criança de meses, sem visitas, à qual se afeiçoou imenso. Passado pouco mais de um ano, a criança saiu para adoção. Contudo, apesar desse processo "a família, que adotou essa menina, mantém contactos com ela, coisa que é muito raro acontecer em termos de projetos de adoção, e de facto ela foi excelente desse ponto de vista, organizou um dossier com fotografias do crescimento da menina com tudo o que era registo, com tudo aquilo que faz parte da história (...) tinha imensas fotografias e gravou cd, fez um álbum, fez não sei quê. Mandou tudo com a menina porque aquela criança tem uma história, e hoje visitam-se, volta e meia visitam-se, ela sabe, tem notícias, manda mensagens de Natal e isto, portanto, é muito gratificante e diz muito das características das pessoas”.

$\mathrm{Na}$ figura 7, pode-se constatar que metade das famílias de origem são classificadas como cooperantes face à colocação da criança ou jovem por 5 famílias de acolhimento, por 7 profissionais da equipa de acolhimento, e pelas 5 famílias de origem, que se autoavaliaram da mesma forma. Destaca-se igualmente uma significativa frequência de classificações de oposição, por 4 acolhedores, 3 profissionais da equipa de acolhimento e 4 famílias de origem. Em concordância encontram-se $80 \%$ dos acolhedores e profissionais da equipa de acolhimento, e $60 \%$ dos acolhedores, profissionais da equipa de acolhimento e famílias de origem. 
Figura 7. A atitude da família de origem face à colocação na perspetiva dos três atores

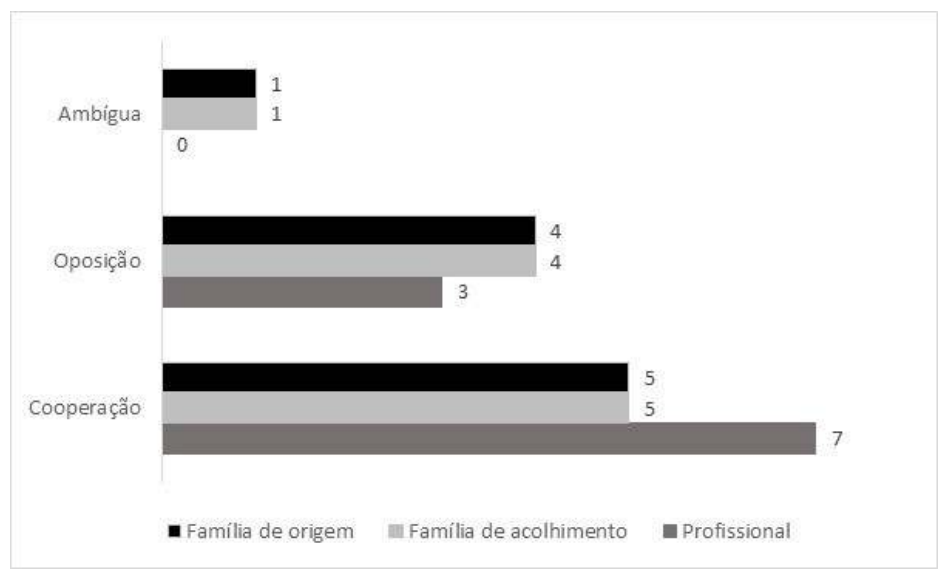

Uma parte das famílias de origem evoluiu da oposição inicial para uma aceitação da separação, por concordar com ela ou porque desenvolveram uma estratégia de adaptação que lhes permite manter a esperança do regresso da criança a sua casa. A FO2, por exemplo, afirma que atualmente "aceito bem as coisas. Calma. Tenho de estar calma”. Todavia, no início da colocação "não aceitava muito, mas agora tenho que aceitar. Foi complicado. Senti-me revoltada. Encostaram-me à parede. Acho que isto não se faz a ninguém. Tirá-los no meio de uma aula, puxá-los. Há outra maneira de fazer as coisas sem ser à bruta. Revoltada. Como se me espetassem uma faca no peito”.

A FO7, por seu turno, face à pergunta: "como se sente atualmente perante a colocação?"

Respondeu: “agora, à vinda para cá, custa mais. Eu quero é ir vê-los. Para cá a gente já vem muito em baixo. Não é que eu seja mais otimista do que ele (refere-se ao pai), mas... Temos de olhar para a frente, por mais que nos custe, por mais que nos doa. Temos de fazer o melhor porque não convém os pais irem abaixo".

P. - E no início da colocação?

- Foi muito doloroso para os três".

Esta evolução é reconhecida pelas famílias de acolhimento. Para a FA1, a atitude inicial da família de origem foi muito agressiva: "Eles ficaram muito revoltados, queriam bater em toda a gente, fizeram para lá muitas coisas. P. - E agora no presente? - Agora no presente está mais... aceitam melhor. Vêm também que o António está muito melhor e aceitam”.

Numa das situações, foi possível preparar a transição da criança para a família de acolhimento (FA2). No início, a mãe estava preocupada se os filhos 
iam ficar bem na nova casa. Os acolhedores fizeram então um apanhado de algumas fotografias que tinham da casa e mostraram-nas à mãe. Foi feita uma preparação pelos técnicos, explicando o que ia acontecer, e só depois os acolhedores foram apresentados à mãe.

P. - E aceitou que ela ficasse aqui colocada?

- Aceitou, lágrima no olho, na mesma, como qualquer mãe. Mas depois olhou para nós e começou a entender que... eu acho que ela pensa «se calhar até está melhor ali», percebe? Muitas das vezes eu penso assim «ela não the quer ligar, mas se calhar ela já não vem à visita mais vezes, porque pensa ela está melhor ali» porque ela é capaz de não ter capacidade e condições para the dar um futuro que..., normal, não é? Também pode ser por esse lado.

P. - E essa atitude de aceitação, porque no fundo a mãe aceitou e perspetivou que a menina estaria bem aqui convosco, mantém-se também agora no presente? Portanto, no início ela aceitou, e agora?

- Tudo normal. Sim, ela aceita.

Noutros casos, a oposição inicial prolonga-se até ao presente, como sucede no caso da FO9, que reclama o regresso imediato da criança:

“Mãe - Acho que já...já é saturante... Já basta, acho que já estava na altura de ele... de o tribunal, ir dar uma perspetiva... [...] Eu sei que sem trabalho... Eu sei também, eu sei. Sei porque eu já vi lá, sei de duas ou três senhoras que não tinham trabalho e as crianças voltaram para casa, mesmo com o Rendimento de Inserção Social. E ficaram na mesma com o Rendimento de Inserção Social e os miúdos voltaram para casa...

Pai - Já basta, já chega, já... É que estão a estragar o miúdo e estão-nos a estragar a nossa vida a nós também. A única coisa que eu queria arranjar, era um emprego para...ter os miúdos em casa... Estamos a perder a infância, a infância dos filhos..."

No ponto de vista dos profissionais, a atitude da família de origem depende do seu consentimento e da forma como se processa a retirada. Situações de oposição associadas a exposição pública geram sentimentos de revolta que demoram tempo a ultrapassar, ou que se prolongam e permanecem no relacionamento com a equipa de acolhimento. É o caso narrado pelo $\mathrm{P} 10$, em que um menino foi retirado de forma violenta, com a presença da polícia. O contexto era muito complicado - tráfico e consumo de drogas -, sem consentimento da mãe, com mandatos judiciais para a retirada, aconteceu a oposição da mãe e das pessoas que viviam no mesmo contexto. Nos dias seguintes acalmou, compreendeu e aceitou a nova situação, porque percebeu que os meninos estavam bem. A oposição foi circunscrita ao momento, que foi 
público, na rua. Contudo, foram as pessoas do meio que se compadeceram com as histórias destes meninos e denunciaram a situação de fome e maus-tratos.

O testemunho do P3 é totalmente diferente: um caso em que a família de origem dá o consentimento e em que ocorre uma visita prévia antes da retirada:

"antes da primeira visita, marcamos uma entrevista com a família de origem, não sabíamos do dia da retirada, para nos conhecerem e ao serviço que prestamos, explicando quem está a acompanhar os filhos, de qual é o nosso papel e o papel da família de acolhimento, de forma a todos os papéis fiquem bem definidos e bem compreendidos. A mãe aceitou a saída da filha e tem a expetativa que os meninos regressem. Está a cumprir as ações com as quais se comprometeu, para que possa obter resultados. (...) neste caso, a mãe vê as pessoas da família de acolhimento como referências, de apoio, cuidadores. Aceita a colocação, sente que estão muito bem cuidados, estão muito melhor e que, no futuro, os terá de volta. É esse o pensamento.”

Em suma, a aceitação e a compreensão possibilitam uma relação positiva entre a família de origem e a de acolhimento. Estes atores foram também questionados face à atitude das crianças e jovens sobre o enquadramento em acolhimento familiar. É possível evidenciar que os acolhedores, os profissionais da equipa de acolhimento e as famílias de origem consideram que as crianças e jovens, na sua maioria apresentam alegria, nomeadamente 7 acolhedores, 7 profissionais da equipa de acolhimento e 5 famílias de origem. Por sua vez, 4 famílias de origem referem que as crianças ou jovens demonstram tristeza ou angústia, assim como 2 profissionais de acompanhamento e uma família de acolhimento (Figura 8). Destaca-se que existe uma concordância significativa entre os acolhedores e os profissionais da equipa de acolhimento. Em contrapartida, apenas existe concordância em $40 \%$ dos casos entre os três atores.

Figura 8. Atitude das crianças e jovens sobre o acolhimento familiar na perspetiva dos atores

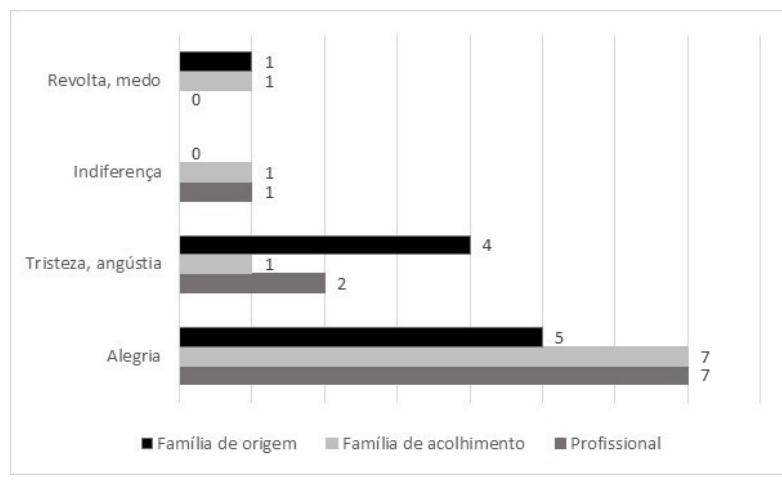


Uma das mães de origem reconhece que a sua filha reage bem, "como eles são bons para ela" (FO1). Para a FO2, "ao princípio foi um impacto para a criança. Foi tirada no meio da aula. Tudo à bruta. Ficou com muitas saudades dos gatitos, pergunta sempre por eles. Penso que foi difícil habituar-se a uma família nova, novas regras...”. P. - E no presente? "Oh, agora? Acho que estão bem. Excelentemente bem". $\mathrm{Na}$ perspetiva das famílias de acolhimento, a integração evoluiu rapidamente do choque e da recusa inicial para o sentimento de integração e de bem-estar. O relato da FA3 é disso testemunho:

"O primeiro dia, pronto, estavam um bocadinho... estavam tímidos, é normal... A Carla é bastante tímida, ela também tem uma autoestima muito baixa. Depois os miúdos, é assim, estavam habituados a dormir juntos, a dormir com a mãe... quer dizer, chegar aqui e a gente dizer «está aqui o teu quarto", claro que é um choque, é uma diferença muito grande, mas, naquele primeiro dia, até os deixei dormir juntos, na mesma cama, no quarto da minha filha e pronto, ela estava muito caladita, quase não falava, nem à mesa, quase que não falavam, quase não comiam.

$\mathrm{P}$ - Atualmente, a atitude dela é diferente?

Muito diferente, completamente...90\%... Porque é assim....agora ela sente-se valorizada, sente-se também acarinhada e a situação dela mudou também radicalmente."

A narrativa da FA5 compara a atitude inicial, em que a criança

"vinha mal, chorava e gritava... veio até como uma funcionária do hospital, vinha muito mal, porque ele deixou a mãe, deixou o tio, porque ele tinha muita adoração por esse tio... Dormiu muito mal e gritou, gritou que se fartou, depois acabou por adormecer... Esteve aí a dormir duas horas e tal, e depois quando acordou, pronto, foi como se se apagasse tudo, não é... comecei a falar com ele."

As respostas dos profissionais alinham na mesma direção. $\mathrm{Na}$ entrevista com o P1, declara-se que a criança

"não levava regras, portanto não sabia estar, não sabia sossegar à mesa $\mathrm{e}$ tinha muitos medos. Não dormia com a porta, a luz apagada, a porta fechada, não queria nada disso porque isso tudo era sinónimo de experiências que ele tinha passado, que o tinham traumatizado. Neste momento é um miúdo cheio de vida, cheio... muito simpático, muito engraçado, com um sentido de humor, com uma tranquilidade...” 
Para o P2, a jovem acolhida já chegou à conclusão de que a mãe não consegue dar-lhe, neste momento, o que ela precisa, como ter uma casa, comida, roupa, poder estudar, tudo aquilo que os seus acolhedores lhe oferecem. As visitas permitem-lhe manter o contacto com a mãe e deste modo, combina o sentimento de bem-estar com a presença da mãe na sua vida. $\mathrm{O}$ processo executivo veio transpor, perante uma maior necessidade de eficácia.

\section{Discussões e conclusões}

As evidências recolhidas apontam para a necessidade de se aperfeiçoar o sistema de comunicação e a interação entre os profissionais, os acolhedores, a criança e a família de origem. Urge clarificar o papel que cabe, nesta teia complexa de relações, a cada um dos atores, para garantir a efetiva proteção e segurança da criança, e para permitir uma avaliação adequada sobre a continuidade do contacto e do próprio acolhimento. A perceção das famílias de origem e de acolhimento são um dado importante para o processo de formação, especialmente dos profissionais que acompanham cada caso.

É interessante constatar que os profissionais são os atores que percecionam menos dificuldades ao nível do contacto. Os acolhedores e as famílias de origem aproximam-se mais neste ponto, uma vez que concordam em $50 \%$ dos casos. Estaremos perante uma desvalorização das dificuldades por parte de quem tutela as colocações e tem o dever de supervisionar as visitas? Ou, pelo contrário, estamos face a uma sobrevalorização das dificuldades por parte dos acolhedores e das famílias de origem? Nos 10 casos analisados, os profissionais só estavam presentes, no momento das visitas, em 4 deles. Este distanciamento pode explicar a divergência de análise relativamente aos outros atores. Outra explicação pode encontrar-se no facto dos profissionais conhecerem diversas situações de contacto no acolhimento familiar, nomeadamente situações em que as visitas decorrem com grande dificuldade. Essa perspetiva global da realidade poderá levar a uma relativização das dificuldades sentidas por acolhedores e pais nestes casos concretos, que seriam, por hipótese, menos complicados do que os outros.

Relativamente ao tipo de dificuldades enunciadas, e apesar da discordância verificada entre os três atores, duas questões sobressaem: a logística do contacto e a referente ao relacionamento entre acolhedores e famílias de origem, por um lado, e profissionais e famílias de origem, por outro. As dificuldades logísticas prendem-se com as deslocações, com os meios de transporte disponíveis e com a despesa que representa para as famílias. Estas dificuldades são ultrapassáveis, podendo o sistema de proteção disponibilizar os recursos que facilitem as viagens e suportem os encargos, de modo a assegurar que a condição financeira não seja uma razão para que estas crianças não se encontrem com os seus familiares. Se as visitas são um direito, o sistema terá o dever correspondente de assegurar as condições necessárias para a sua concretização, nomeadamente as económicas. 
Numa situação de vulnerabilidade, com os filhos retirados de casa para passarem a viver com outra família, é essencial garantir as condições materiais indispensáveis para que os pais realizem as visitas, excluindo obviamente as situações em que o tribunal entenda que os contactos são lesivos do bem-estar da criança acolhida. Com efeito, o contacto pode ser suspenso temporariamente, ou mesmo cessar, se houver o risco de que a visita seja um momento de recordação do trauma ou mesmo um momento de repetição dos maus tratos. Nestas circunstâncias, devem ser proporcionadas explicações ajustadas à idade e capacidade de compreensão da criança.

As dificuldades associadas ao relacionamento não se resolvem de modo tão pragmático. Implicam um longo processo de acompanhamento educativo das várias partes envolvidas, requerendo tempo, sensibilidade e empenho, para se procurar ultrapassar as dificuldades. A formação/supervisão pode desempenhar neste domínio um papel significativo, se contribuir para esclarecer os processos, as fases em que se desdobram, os papéis de cada ator, as finalidades da intervenção e as decisões a tomar, numa perspetiva longitudinal. O contacto pode caracterizar-se pela cooperação ou pelo conflito, mas também pela indiferença ou pela ambiguidade, sendo essencial avaliar as especificidades de cada caso, e a forma como vai evoluindo.

Para os profissionais, as famílias de origem são menos cooperantes e opõem-se menos à colocação do que para as famílias de acolhimento. Uma vez mais, os profissionais têm uma perspetiva mais otimista sobre o desenrolar do acolhimento e sobre a evolução da atitude das famílias de origem.

$\mathrm{Na}$ apreciação da qualidade da relação, a avaliação mais positiva surge no par constituído pelas famílias de acolhimento e pelos profissionais. A relação desequilibra-se, pelo contrário, no modo como as famílias de acolhimento e as famílias de origem se percecionam, uma vez que as últimas têm uma perceção mais positiva das primeiras. O reconhecimento pelo trabalho prestado, a integração e o desenvolvimento dos filhos pode explicar esta apreciação por parte das famílias de origem. Comportamentos agressivos e o incumprimento do estabelecido são críticas endereçadas pelos acolhedores às famílias de origem, numa dinâmica relacional que tem como pano de fundo a diversidade cultural e os desafios que coloca, quando confronta os intervenientes com comportamentos e valores distintos dos seus. O contacto permite esta confrontação de todos os envolvidos e, particularmente, da família de acolhimento com a necessidade de lidar frequentemente com as diferenças nos comportamentos, hábitos e valores, exigindo-lhe a capacidade de compreender e aceitar modos de vida distintos, sem preconceitos, aceitação essa que não pode, todavia, prescindir de princípios e dos direitos humanos essenciais, como o respeito pela liberdade e pela dignidade do ser humano. Os acolhedores devem estar preparados e ser capazes de estabelecer limites, de resistir à tentação de se oporem de modo injustificado aos contactos ou, pelo contrário, de aceitarem passivamente todos os comportamentos 
e atitudes. Trata-se, no fundo, de evitar o conflito ou o corte no relacionamento, e promover em contrapartida uma "cooperação regulada", sendo que a formação sobre o contacto e a diversidade cultural pode reforçar a capacidade comunicacional e relacional de todos os intervenientes no acolhimento.

Por outro lado, o trabalho desenvolvido junto dos pais, de apoio à separação, no acompanhamento do contacto e, especialmente, a intervenção socioeducativa visando a recuperação das competências parentais, é essencial para evitar ou, no mínimo, diminuir o incumprimento, de modo a se perspetivar o regresso da criança. Note-se que o incumprimento pode ou não refletir a vontade das FO em realizar as visitas, e pode estar associado aos custos da deslocação, ao local, que pode ser considerado menos acessível ou conveniente, ou à distância entre a morada da FO e da CJ.

No panorama atual, o escasso número de FA em atividade dificulta a escolha de uma colocação que seja próxima da morada da FO, supondo que essa proximidade não é considerada inadequada pela entidade que determina o acolhimento. Esta dificuldade só poderá ser gradualmente superada com a realização de campanhas de seleção e recrutamento que possam aumentar o número de FA, garantindo que elas passem a existir nos diferentes distritos e regiões do território nacional, e que não se localizam somente, como agora, em certos distritos do norte do país.

Para além do consentimento, outro fator que influencia a aceitação da colocação, logo no seu início, é a possibilidade de se preparar a transição da criança. Pelo contrário, quando a retirada é súbita, sem acordo e em locais de maior exposição pública, acentua-se a oposição da família de origem. Nestas circunstâncias, justifica-se um trabalho de acompanhamento mais frequente e intenso, que procure informar os pais relativamente à decisão tomada, ao acolhimento familiar, ao novo contexto de vida do seu filho/a, e ao que poderá suceder no futuro.

Os profissionais precisam de dispor do tempo necessário para programar as visitas e trabalhar a relação entre famílias, de modo a diminuir as representações negativas existentes. Deste modo será possível sensibilizar e responsabilizar as famílias de origem para a importância de cumprirem o plano de visitas, aproveitando, simultaneamente, os momentos de contacto para reforçarem os laços emocionais e afetivos com os seus filhos.

$\mathrm{O}$ acolhimento familiar revela ser, nestes casos analisados, um contexto protetor, capaz de desenvolver as competências das crianças nas principais dimensões das suas vidas, reconhecem, assim como os acolhedores e os profissionais. Esta perceção não é inteiramente partilhada pelas famílias de origem, sendo esse distanciamento um sintoma da necessidade de se acompanhar, com maior proximidade, o caminho que estas famílias também têm de percorrer, para darem um novo sentido ao momento em que se encontram com os seus filhos, para poderem cumprir o seu papel e terem a oportunidade de crescer com os seus filhos. 
Por último, as diferenças de perceção entre os vários atores apontam para a necessidade de aumentar a simetria de informação sobre os mesmos factos, porventura, uma melhor comunicação entre as partes envolvidas no processo de acolhimento familiar, a qual poderia e deveria ser liderada pelos profissionais que supervisionam cada caso, no pressuposto que lhes sejam dados os recursos humanos, materiais e de tempo necessários para o efeito.

\section{Referências bibliográficas}

COURTNEY, Mark E., IWANIEC, Dorota (Eds.) (2009), Residential care of children, New York, Oxford University Press.

CARVALHO, João M. S., DELGADO, Paulo (2014), "Contact in Foster Care: Bridge or Collision Between Two Worlds?”, Journal of Applied Research on Children, 5(1), Article 10.

CAIRNS, Kate (2012), Attachment, trauma and resilience: therapeutic caring for children, London, BAAF.

COAKLEY, Tanya M. (2013), "The influence of father involvement on child welfare permanency outcomes: A secondary data analysis", Children and Youth Services Review, 35(1), 174-182.

COMISSÃO NACIONAL DE PROMOÇÃO DOS DIREITOS E PROTEÇÃO DAS CRIANÇAS E JOVENS (2016), Relatório de Avaliação da Atividade - 2016, Lisboa, Autor.

DEL VALLE, Jorge F., BRAVO, Amaia (2013), "Current trends, figures and challenges in out of home child are: An international comparative analysis”, Psychosocial Intervention, 22, 251257. doi:10.5093/in2013a28

DELGADO, Paulo (2011), O acolhimento familiar de crianças. Uma perspectiva ecológica, Porto, Profedições.

DELGADO, Paulo, PINTO, Vânia, CARVALHO, João M. S. (2014), "O contacto no acolhimento familiar e o desafio da diversidade”, in G. Pérez Serrano e A. De-Juanas Oliva (Coord.), Educación y jóvenes en tiempos de cambio, Madrid, UNED - Universidad Nacional a Distancia, pp. 117-126.

DElGADO, Paulo (Coord.), CARVALHO, João M. S., SOUSA, Alexandra, BERTÃO, Ana, MOREIRAS, Dulce, TIMÓTEO, Isabel, OLIVEIRA, Joana, et al. (2016), O contacto no acolhimento familiar. O que pensam as crianças, as famílias e os profissionais, Porto, Mais Leitura.

FOXON, Judith, FULLER, Rachel (2007), Spark learns to fly, London, BAAF.

GARBARINO, James, Eckenrode, John (1999), "El significado del maltrato”, in J. Garbarino e J. Eckenrode (Eds.), Porque las famílias abusan de sus hijos, Barcelona, Granica, pp. 15-44.

GILBERT, Neil, PARTON, Nigel, SKIVENES, Marit (2011), Child Protection Systems, New York, Oxford University Press.

INSTITUTO DA SEGURANÇA SOCIAL, I.P. (2017), Casa 2016. Relatório de Caraterização Anual da Situação de Acolbimento das Crianças e Jovens, Lisboa, Instituto da Segurança Social.

McWEY, Lenore (2000), "I Promise to Act Better if You Let Me See My Family: Attachment Theory and Foster Care Visitation", Journal of Family Social Work, 5(1), 91-106.

McWEY, Lenore, MULLIS, Anne (2004), "Improving the Lives of Children in Foster Care: The Impact of Supervised Visitation", Family Relations, 53(3), 293-300.

McWEY, Lenore, ACOCK, Alan, PORTER, Breanne (2010), "The impact of continued contact with biological parents upon the mental health of children in foster care", Children and Youth Services Review, 32(10), 1338-1345. 
MOYERS, Sue, FARMER, Elaine, LIPSCOMBE, Jo (2006), "Contact with family members and its impact on adolescents and their foster placements", The British Journal of Social Work, 36(4), 541-559.

OSBORN, Alexandra, DELFABBRO, Paul (2009), "Foster carers perceptions of the effects of parental contact upon children's psychosocial wellbeing in long-term foster care", Communities, Children and Families Australia, 4(2), 18-33.

SEN, Robin, BROADHURST, Karen (2011), "Contact between children in out-of-home placements and their family and friends networks: a research review", Child and Family Social Work, 16(3), 298-309.

TRISELIOTIS, John (2010), “Contact between looked after children and their parents: a level playing field", Adoption \& Fostering, 34(3) 59-66.

VANDERFAEILLIE, Johan, VAN HOLEN, Frank, COUSSENS, Sofie (2008), "Why do foster care placements break down? A study into the factors influencing foster care placement breakdown in Flanders", International Journal of Child and Family Welfare, 11(2-3), 77-87.

RODRIGUES, Benjamim Silva (2015a), Ventos de Mudança na Vida Profissional dos Solicitadores e Agentes de Execução: uma nova (des)ordem, ética e deontologia profissional (?). Tomo I, Lisboa, Rei dos Livros.

RODRIGUES, Benjamim Silva (2015b), Ventos de Mudança na Vida Profissional dos Solicitadores e Agentes de Execução: uma nova (des)ordem, ética e deontologia profissional (?). Tomo II, Lisboa, Rei dos Livros.

RODRIGUES, Benjamim Silva (2015c), Ventos de Mudança na Vida Profissional dos Solicitadores e Agentes de Execução: uma nova (des)ordem, ética e deontologia profissional (?). Tomo III, Lisboa, Rei dos Livros.

RODRIGUES, Maria de Lurdes (2002), Sociologia das Profissões, Oeiras, Celta Editora.

SANTOS, Boaventura de Sousa (dir.) (2007), A Acção Executiva em Avaliação: Uma Proposta de Reforma, Observatório Permanente da Justiça Portuguesa, Centro e Estudos Sociais, Faculdade de Economia Universidade de Coimbra.

SANTOS, Boaventura de Sousa (2015), Para uma revolução democrática da justiça, Coimbra, Almedina. 